\title{
Repercussões da pandemia de coronavírus na saúde mental dos profissionais de enfermagem: revisão sistemática qualitativa
}

\author{
Repercussions of the pandemic of coronavirus in the mental health of nursing professionals: \\ qualitative systematic review
}

Repercusiones de la pandemia del coronavirus en la salud mental de los profesionales de enfermería: revisión sistemática cualitativa

\begin{abstract}
Resumo
Objetivou-se analisar as evidências científicas sobre as repercussões da pandemia de coronavírus na saúde mental dos profissionais da enfermagem. Realizou-se um estudo de revisão sistemática. Para a busca foi feito um levantamento de dados através da busca na Biblioteca Virtual em Saúde (BVS) nas bases de dados eletrônicas utilizadas na pesquisa: PubMed (Biblioteca Nacional de Medicina do Instituto Nacional de Saúde dos Estados Unidos), SCIELO (Scientific Eletronic Library Online), LILACS (Literatura Latino-Americana e do Caribe em Ciências da Saúde), BDENF (Base de Dados da Enfermagem), e Google Acadêmico, no período de 2020 a 2021. Foram utilizados os descritores "Covid-19"; "Pandemias"; "infecções"; "Saúde Mental"; "Enfermagem". Foram encontrados um total de 358 artigos relacionados com o tema. Logo após foram aplicados os critérios de inclusão e exclusão restando 63 artigos. Foram selecionados 37 estudos para compor está revisão sistemática. Diante dos resultados os estudos apontaram grandes impactos na saúde mental desses colaboradores que levaram o desenvolvimento da depressão, ansiedade, síndrome de burnout e estresse pós-traumático. a partir dos artigos analisados emergiram 3 categorias: A Enfermagem no contexto da pandemia do Covid-19; Impactos na saúde mental dos profissionais de enfermagem durante a pandemia da Covid-19; Recursos de apoio dos profissionais de enfermagem no enfrentamento ao Covid-19, para discussão da temática. Conclui-se que a presente pesquisa foi possível enfatizar a importância dos profissionais de enfermagem no enfretamento do novo coronavírus, mais ao mesmo tempo desgastante por diversos fatores como a desvalorização desses colaboradores, acarretando vários impactos no adoecimento psíquico desses trabalhadores.
\end{abstract}

Palavras-chave: Covid-19; Pandemias; Infecções; Saúde mental; Enfermagem.

\begin{abstract}
The objective was to analyze the scientific evidence on the repercussions of the coronavirus pandemic on the mental health of nursing professionals. A systematic review study was carried out. For the search, a data collection was carried out by searching the Virtual Health Library (VHL) in the electronic databases used in the research: PubMed (National Library of Medicine of the National Institute of Health of the United States), SCIELO (Scientific Electronic Library Online), LILACS (Latin American and Caribbean Literature on Health Sciences), BDENF (Nursing Database), and Academic Google, from 2020 to 2021. The descriptors "Covid-19" were used; "Pademics"; "infections"; "Mental health"; "Nursing". A total of 358 articles related to the topic were found. Soon after, the inclusion and exclusion criteria were applied, leaving 63 articles. 37 studies were selected to compose this systematic review. In view of the results, the studies showed great impacts on the mental health of these employees, which led to the development of depression, anxiety, burnout syndrome and post-traumatic stress. From the analyzed articles, 3 categories emerged: Nursing in the context of the Covid-19 pandemic; Impacts on the mental health of nursing professionals during the Covid-19 pandemic; Support resources for nursing professionals in coping with Covid-19, for discussion of the subject. It is concluded that this research was possible to emphasize the importance of nursing
\end{abstract}


professionals in dealing with the new coronavirus, which is more at the same time exhausting due to several factors such as the devaluation of these employees, causing several impacts on the psychological illness of these workers.

Keywords: Covid-19; Pandemics; Infections; Mental health; Nursing.

\section{Resumen}

El objetivo fue analizar la evidencia científica sobre las repercusiones de la pandemia de coronavirus en la salud mental de los profesionales de enfermería. Se realizó un estudio de revisión sistemática. Para la búsqueda se realizó una recolección de datos mediante la búsqueda de la Biblioteca Virtual en Salud (BVS) en las bases de datos electrónicas utilizadas en la investigación: PubMed (Biblioteca Nacional de Medicina del Instituto Nacional de Salud de los Estados Unidos), SCIELO (Scientific Electronic Library Online), LILACS (Literatura Latinoamericana y del Caribe en Ciencias de la Salud), BDENF (Base de Datos de Enfermería) y Google Académico, de 2020 a 2021 . Se utilizaron los descriptores "Covid-19"; "Pademicos"; "Infecciones"; "Salud mental"; "Enfermería". Se encontraron un total de 358 artículos relacionados con el tema. Poco después se aplicaron los criterios de inclusión y exclusión, quedando 63 artículos. Se seleccionaron 37 estudios para componer esta revisión sistemática. A la vista de los resultados, los estudios mostraron grandes impactos en la salud mental de estos empleados, lo que derivó en el desarrollo de depresión, ansiedad, síndrome de burnout y estrés postraumático. De los artículos analizados surgieron 3 categorías: Enfermería en el contexto de la pandemia Covid-19, Impactos en la salud mental de los profesionales de enfermería durante la pandemia Covid-19; Recursos de apoyo a los profesionales de enfermería en el afrontamiento del Covid-19, para la discusión del tema. Se concluye que esta investigación permitió enfatizar la importancia de los profesionales de enfermería en el abordaje del nuevo coronavirus, que es más a la vez agotador por varios factores como la devaluación de estos empleados, provocando varios impactos en la enfermedad psicológica de estos trabajadores.

Palabras clave: Covid-19; Pademicos; Infecciones; Salud mental; Enfermería.

\section{Introdução}

Desde o final de 2019, a humanidade vem sendo acometida pela pandemia do novo coronavírus ou Covid-19, interferindo diretamente na rotina das pessoas, impondo novos hábitos e novas regras. Trata-se de uma infecção respiratória aguda causada pelo coronavírus SARS-CoV-2, potencialmente grave, de elevada transmissibilidade e de distribuição global (Brasil, 2020a). É uma doença cruel e a cada dia, testa a capacidade do sistema de saúde em lidar com os problemas derivados desse vírus, repercutindo nos fatores sociais e econômicos, que geram incertezas diárias nas condutas que se deve tomar (Alves \& Ferreira, 2020).

A pandemia de Covid-19 é uma emergência global e é indiscutível a ênfase que se dá às preocupações em como conter a disseminação do vírus, a proposição de planos nacionais, requerimentos de vacinas e medicamentos, uma atuação implacável da vigilância epidemiológica ea grande preocupação em como manter o sistema econômico funcionando (Oliveira et al., 2020). Por ser altamente contagiosa, as medidas de prevenção e controle de infecção devem ser rigorosamente implementadas (Souza et al., 2021), como o isolamento e o distanciamento social, o uso de máscaras, a lavagem das mãos e a higienização com álcool em gel ou álcool 70\% (Opas, 2020). A transmissão ocorre principalmente, pelas vias respiratórias por meio da inalação de gotículas e/ou aerossóis através do contato direto entre as pessoas e objetos contaminados pelo vírus (Moreira \& Lucca, 2020).

Segundo a Organização Mundial de Saúde (OMS), a maioria das pessoas infectadas apresenta a forma leve da doença, com alguns sintomas como mal-estar, febre, fadiga, tosse, dispneia leve, anorexia, dor de garganta, dor no corpo, dor de cabeça ou congestão nasal, sendo que algumas também podem apresentar diarreia, náusea e vômito (Who, 2019). Pessoas idosas, com condições crônicas pré-existentes, como diabetes e hipertensão, doença pulmonar crônica ou asma de moderada a grave, imunossuprimidos (câncer, HIV+, transplantados, doenças imunológicas, em uso prolongado de corticóides e outros medicamentos imunossupressores), doenças cardíacas, insuficiência renal, doenças hepáticas, obesas e tabagistas são consideradas do grupo de risco (Brasil, 2020b).

Num cenário de pandemia deve ser considerado que toda a população experimente tensões e angústias em maior ou menor grau, sendo esperado um aumento da incidência de transtornos psíquicos, embora se deva destacar que nem todos os 
problemas psicológicos apresentados poderão ser qualificados como doenças, a maioria será reações normais de uma situação anormal (Brasil, 2020c).

Infelizmente, entre as fragilidades destacadas em um cenário nada equilibrado, um aspecto tornou-se preocupante: a saúde mental dos profissionais de enfermagem (Ramos-toescher et al., 2020). Esses assumem uma posição de grande relevância no sistema de saúde, cujo trabalho é centrado no cuidado, envolvendo uma ligação direta entre profissional/paciente. Barbosa et al., (2020) afirmam que os profissionais de enfermagem estão acostumados a lidar com situações de estresse e necessidade de tomada rápida de decisão, entretanto, o cenário atual é novo levando a urgência de conhecimento técnico e estratégias bem como equilíbrio psicoemocional.

Frente à situações de estresse constante, os enfermeiros apresentam maior predisposição para sofrimento mental, sendo a depressão uma das doenças que mais os acometem, devido à natureza da atividade que desenvolvem; que estão diretamente relacionadas a sofrimentos físicos e emocionais daqueles a quem estes prestam seus serviços, e das condições de trabalho e falta de reconhecimento profissional (Santos et al., 2020). E devido a essa sobrecarga mental surgi a Síndrome de Burnout, que é caracterizado por um estado emocional exaustão, os enfermeiros experimentam graves problemas psicológicos e mentais que podem levar ao esgotamento e, em seguida, à redução da produtividade, erros em ambientes clínicos e falta de preocupação em lidar com os pacientes (Galanis et al., 2021).

A presente pesquisa se justifica com base no atual cenário mundial que estamos enfrentando, a pandemia do Covid19, onde os casos estão mais frequentes e tem grande repercussão na mídia. O coronavírus e suas consequências têm afetado diretamente na rotina da população em diversas esferas, e é o foco de discussões no mundo todo. Com o avanço da doença a morbidade e a mortalidade estão aumentando cada vez mais, portanto tem sido desafiador para os profissionais de saúde, especialmente os da enfermagem que estão na linha de frente para combater ou diminuir os casos de Covid-19. Teve como objetivo geral analisar as evidências científicas sobre as repercussões da pandemia de coronavírus na saúde mental dos profissionais da enfermagem.

\section{Metodologia}

O presente trabalho foi realizado através de uma revisão sistemática, que é um método de revisão que desempenha muitas funções críticas; podem fornecer sínteses do estado do conhecimento em um campo, a partir do qual as futuras prioridades de pesquisa podem ser identificadas; além de identificar problemas na pesquisa primária para serem corrigidos em estudos futuros; e gerar ou avaliar teorias sobre como ou por que os fenômenos ocorrem (Page et al., 2021).

Trata-se de uma pesquisa bibliográfica de revisão sistemática que é um método que permite maximizar o potencial de uma busca, encontrando o maior número possível de resultados de uma maneira organizada, construída em oito etapas: 1 Delimitação da questão a ser pesquisada; 2 - Escolha das fontes de dados; 3 - Eleição das palavras-chave para a busca; 4 Busca e armazenamento dos resultados; 5 - Seleção de artigos pelo resumo, de acordo com critérios de inclusão e exclusão; 6 Extração dos dados dos artigos selecionados; 7 - Avaliação dos artigos; 8 -Síntese e interpretação dos dados. O presente estudo teve como questão norteadora: Quais as repercussões da pandemia de coronavírus na saúde mental dos profissionais de enfermagem?

O levantamento dos dados foi realizado através do acesso a banco de dados online, entre os meses de agosto e setembro de 2021, através da busca de artigos científicos indexados na BVS (Biblioteca Virtual de Saúde), utilizando as seguintes bases de dados: PubMed (Biblioteca Nacional de Medicina do Instituto Nacional de Saúde dos Estados Unidos), BDENF (Base de Dados da Enfermagem), LILACS (Literatura Latino-Americana e do Caribe em Ciências da Saúde), SciELO (Scientific Eletronic Library Online) e MedLine (Medical Literature Analysis and Retrievel System Oline). Foram utilizados os seguintes descritores: "Covid-19", "Pandemias", "Saúde Mental”, "Infecções", "Enfermagem”, conforme 
orientação dos Descritores em Ciências da Saúde (DeCS) da Biblioteca Virtual em Saúde (BVS). Como estratégia de busca foi realizada o cruzamento dos descritores com o operador booleano "AND".

Adotou-se como critérios de inclusão: artigos primários de abordagem qualitativa que tinham como participantes de pesquisa os profissionais de enfermagem que atuavam na linha de frente do Covid-19, artigos de revisão publicados entre 2020 e 2021, nos idiomas português, espanhol e inglês. Os critérios adotados para exclusão foram: artigos duplicados (repetidos), que não tinham relação com a temática, relatos de experiências e sem acesso ao texto completo de maneira gratuita.

Após realizar a leitura exploratória dos títulos e resumos foram selecionados os que referem à temática das repercussões da pandemia de coronavírus na saúde mental dos profissionais de enfermagem, utilizando a estratégia de busca PICo (Quadro 1).

Quadro 1. Descrição da estratégia PICo. Teresina, Piauí, Brasil, 2021.

\begin{tabular}{|c|c|c|}
\hline ACRÔNIMO & DEFINIÇÃO & DESCRIÇÃO \\
\hline P & População, Paciente ou Problema & Profissionais de Enfermagem \\
\hline I & Interesse & Pandemia do Coronavírus \\
\hline Co & Contexto & Repercussões na Saúde Mental \\
\hline
\end{tabular}

Fonte: Autores (2021).

Os dados foram coletado a partir de um formulário semi-estruturado detalhado e subdividido em Perfil das Produç̃es e Resultados em evidências de acordo com a hipótese estabelecida, os critérios de inclusão e exclusão de artigos, a definição das informações a serem extraídas dos artigos selecionados, a apresentação dos resultados, análise e discussão dos resultados.

Ao final do processo foram encontrados um total de 358 artigos relacionados com o tema: 9 artigos na BDENF, 34 artigos na LILACS, 51 artigos na SciELO, 59 artigos na MedLine e 205 na PubMed. Foram identificados e excluídos 9 artigos duplicados, restando 349. Após a leitura dos títulos e resumos foram excluídos 232 artigos que não atenderam aos critérios de inclusão, restando 63 artigos. Logo após a leitura na íntegra, foram excluídos 26 estudos que não atenderam os critérios de inclusão, restando 32 artigos. A partir desses artigos selecionados 5 foram incluídos no estudo, encontrados a partir de citações, ficando 37 artigos para compor está revisão sistemática. Para apresentação da seleção dos estudos, foi utilizado o fluxograma da Preferred Reporting Items for Systematic Reviews and Meta Analyses (PRISMA), como critério para realizar a leitura dos artigos, realizando a categorização dos achados, distribuindo em artigos excluídos e incluídos, com enfoque nas estratégias que viabilizam o processo. O método PRISMA foi utilizado como critério para realizar a leitura dos artigos, realizando a categorização dos achados, distribuindo em artigos excluídos e incluídos, com enfoque nas estratégias que viabilizam o processo.

Para Gomes (2014) é primordial a leitura dos materiais selecionados, de forma completa, além da elaboração de pressupostos iniciais que servirão de baliza para a análise e a interpretação do material, logo após serão escolhidas formas de classificação inicial, como também serão determinados os conceitos teóricos que orientarão a análise.

O estudo foi idealizado por dois revisores de forma independente, sendo encaminhados para um orientador, com o intuito de revisar a pesquisa, para melhorar a organização e condensação dos dados, considerando o proposto na pesquisa. 
Figura 1. Fluxograma do processo de seleção dos estudos recomendada pela PRISMA.

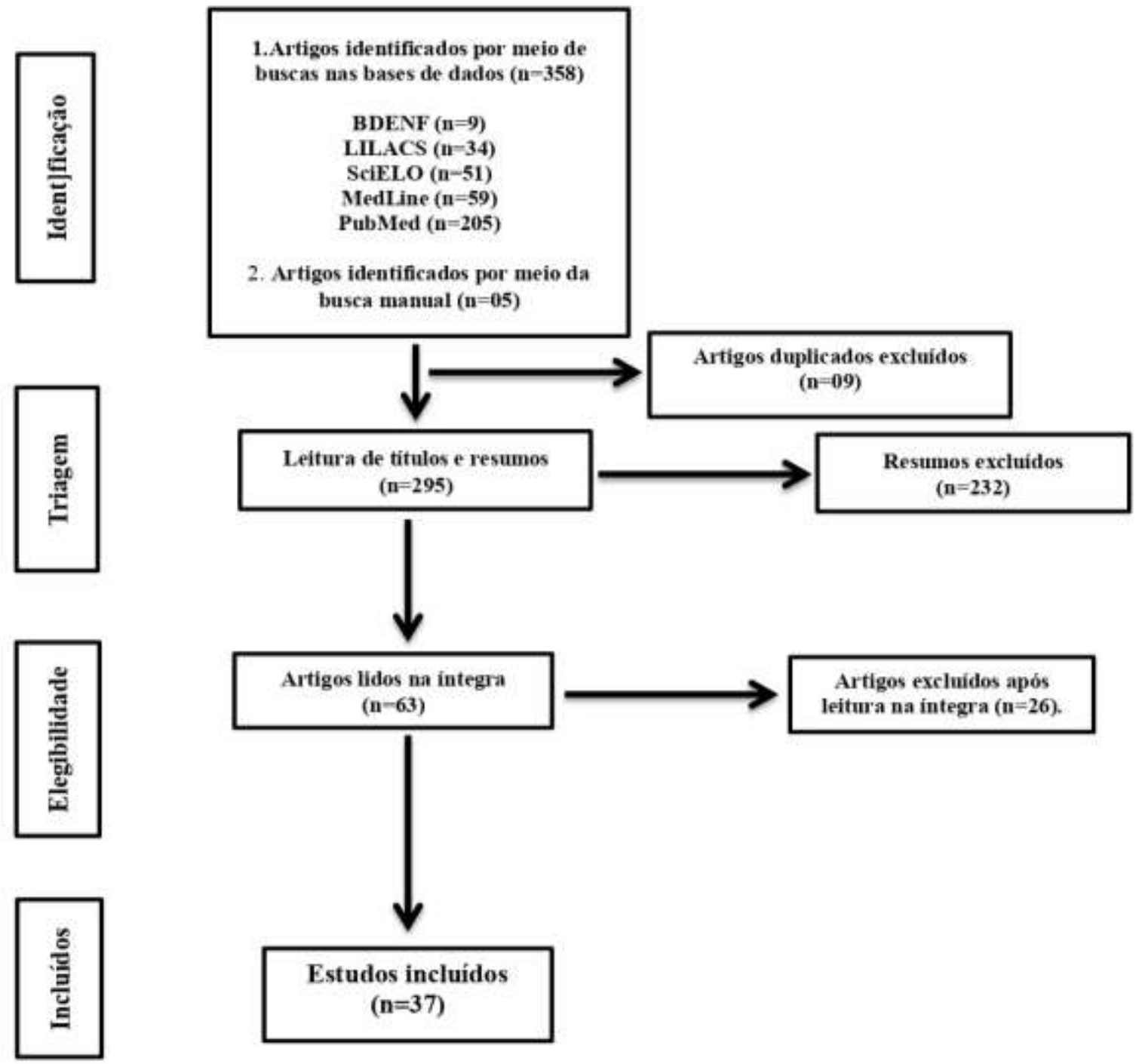

Fonte: Autores (2021).

Os 37 artigos selecionados foram lidos para determinar quais informações seriam extraídas, para serem usadas no presente estudo. Estes artigos foram caracterizados com o auxílio de um formulário estruturado de artigos para armazenar os dados referentes aos aspectos metodológicos e temáticos dos estudos, incluindo as seguintes informações: autores, ano e periódicos de publicação, objetivos e resultados da pesquisa.

\section{Resultados e Discussão}

Os 37 artigos selecionados pela estratégia de busca foram organizados de acordocom autores/ano, título do artigo, periódicos, objetivos e resultados (Quadro 2). O tema Repercussões da pandemia de Coronavírus na saúde mental dos profissionais de enfermagem foi identificado em todos os artigos selecionados. 
Quadro 2. Caracterização dos estudos selecionados por autores, ano, título do artigo, periódico, objetivos, e resultados da publicação.

\begin{tabular}{|c|c|c|c|c|}
\hline $\begin{array}{c}\text { AUTORES/ } \\
\text { ANO }\end{array}$ & TÍTULO DO ARTIGO & PERIÓDICO & OBJETIVOS & RESULTADOS \\
\hline $\begin{array}{l}\text { Alencastro e } \\
\text { Melo. 2021. }\end{array}$ & $\begin{array}{l}\text { REFLEXÕES ACERCA DA } \\
\text { "INFODEMIA" } \\
\text { RELACIONADA } \\
\text { COVID-19 }\end{array}$ & $\begin{array}{l}\text { Revista Mineira } \\
\text { de Enfermagem. }\end{array}$ & $\begin{array}{l}\text { Refletir sobre os impactos } \\
\text { negativos que a disseminação } \\
\text { desenfreada de notícias sobre a } \\
\text { COVID-19 pode trazer para a } \\
\text { saúde e para a sociedade. }\end{array}$ & $\begin{array}{l}\text { A infodemia causou grandes impactos psicológicos, sociais na } \\
\text { saúde mental e na vida dos profissionais de enfermagem que } \\
\text { estão na linha de frente para o combate da pandemia de } \\
\text { coronavírus, aumentando o estresse, a ansiedade, a depressão, } \\
\text { a angústia e a insônia, afetando a prestação de cuidados aos } \\
\text { pacientes. Além disso, as divulgações feitas nas mídias } \\
\text { aumentaram o colapso nos serviços de saúde, fazendo com que } \\
\text { a população se preocupasse ainda mais com a saúde, como } \\
\text { confundir um resfriado e uma dispneia como sintomas da } \\
\text { Covid-19. }\end{array}$ \\
\hline $\begin{array}{l}\text { Cho et } \\
\text { al.,2021 }\end{array}$ & $\begin{array}{l}\text { Factors affecting frontline } \\
\text { Korean nurses' mental health } \\
\text { during the COVID-19 } \\
\text { pandemic. }\end{array}$ & Int Nurs Rev & $\begin{array}{l}\text { Identificar os fatores que } \\
\text { afetam o medo, ansiedade e } \\
\text { sintomas depressivos entre os } \\
\text { da linha de frente enfermeiros } \\
\text { que trabalham com COVID-19 } \\
\text { pacientes ou estão em carga de } \\
\text { COVID-19 triagem na Coréia. }\end{array}$ & $\begin{array}{l}\text { Cuidar de pacientes que são COVID-19-positivo o aumento } \\
\text { dos níveis de medo, ansiedade e sintomas depressivos de } \\
\text { enfermeiros. O clima de segurança do hospital influenciou o } \\
\text { bem-estar mental entre os enfermeiros. }\end{array}$ \\
\hline $\begin{array}{l}\text { Crowe et al., } \\
2021\end{array}$ & $\begin{array}{l}\text { The effect of COVID-19 } \\
\text { pandemic on the mental } \\
\text { health of Canadian critical } \\
\text { care nurses providing patient } \\
\text { care during the early phase } \\
\text { pandemic: A mixed method } \\
\text { study. }\end{array}$ & $\begin{array}{ll}\text { Intensive } & \text { Crit } \\
\text { Care Nurs. } & \end{array}$ & $\begin{array}{l}\text { O estudo teve como objetivo } \\
\text { examinar a saúde mental de } \\
\text { Enfermeiros Registrados em } \\
\text { Cuidados Críticos que prestam } \\
\text { cuidados diretos ao paciente } \\
\text { durante a fase inicial da } \\
\text { pandemia COVID-19 no } \\
\text { Canadá. }\end{array}$ & $\begin{array}{l}\text { O sofrimento psicológico foi descrito como ansiedade, } \\
\text { preocupação, angústia e medo relacionados a mudança rápida } \\
\text { de políticas e informações, comunicação opressiva e pouco } \\
\text { clara, atendimento às necessidades de atendimento ao paciente } \\
\text { de novas maneiras, mantendo-se seguro, egerenciamento de } \\
\text { casa e compromissos pessoais consigo mesmo efamília . }\end{array}$ \\
\hline $\begin{array}{l}\text { Davi et al,. } \\
2021\end{array}$ & $\begin{array}{l}\text { Pandemia, conjunturas de } \\
\text { crise e prática profissional: } \\
\text { qual o papel da enfermagem } \\
\text { diante da Covid-19? }\end{array}$ & $\begin{array}{l}\text { Revista Gaúcha } \\
\text { de Enfermagem }\end{array}$ & 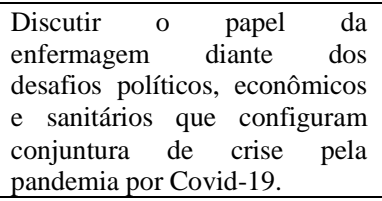 & $\begin{array}{l}\text { As questões centrais relativas ao cenário político-econômico e } \\
\text { sanitário brasileiro são problematizadas, com destaque para o } \\
\text { aprofundamento da desigualdade social. Debate-se o papel da } \\
\text { enfermagem considerando os impactos na saúde destes } \\
\text { trabalhadores, e a relevância da sua atuação nos diversos } \\
\text { cenários de prática profissional e na defesa da proteção social. }\end{array}$ \\
\hline $\begin{array}{l}\text { Duarte, Silva } \\
\text { e Bagatini, } \\
2021 .\end{array}$ & $\begin{array}{l}\text { Enfermagem e saúde mental: } \\
\text { uma reflexão em meio à } \\
\text { pandemia de coronavírus }\end{array}$ & $\begin{array}{l}\text { Revista Gaúcha } \\
\text { de Enfermagem. }\end{array}$ & $\begin{array}{l}\text { Refletir sobre a saúde mental } \\
\text { dos profissionais } \quad \text { de } \\
\text { enfermagem no contexto na } \\
\text { pandemia de coronavírus. }\end{array}$ & $\begin{array}{l}\text { Os estudos analisados, somados à prática assistencial, têm } \\
\text { evidenciado que os profissionais de enfermagem são } \\
\text { suscetíveis à exacerbação de sintomas como depressão, } \\
\text { ansiedade, insônia, angústia, estresse, em meio à pandemia de } \\
\text { coronavírus, tendo em vista os turnos exaustivos de trabalho, a } \\
\text { morte de pacientes, risco de autocontaminação e de seus } \\
\text { familiares e isolamento social. }\end{array}$ \\
\hline $\begin{array}{ll}\text { Fontanini et } \\
\text { al., (2021) }\end{array}$ & $\begin{array}{l}\text { Italian Nurses' experiences } \\
\text { during the COVID-19 } \\
\text { pandemic: a qualitative } \\
\text { analysis of internet posts./ } \\
\text { Experiências de enfermeiras } \\
\text { italianas durante a pandemia } \\
\text { COVID-19: uma análise } \\
\text { qualitativa de postagens na } \\
\text { Internet. }\end{array}$ & $\begin{array}{ll}\text { Revista: } & \text { Int } \\
\text { Nurs Ver } & \end{array}$ & $\begin{array}{l}\text { Investigar a experiência de } \\
\text { enfermeiras italianas durante a } \\
\text { primeira onda do surto } \\
\text { COVID-19 por meio da análise } \\
\text { de postagens profissionais nas } \\
\text { redes sociais. }\end{array}$ & $\begin{array}{l}\text { Várias implicações psicológicas, físicas, sociais e profissionais } \\
\text { emergiram dos enfermeiros que trabalharam durante a } \\
\text { pandemia COVID-19. Apesar de muito elogiados, os } \\
\text { enfermeiros perceberam que falharam em reabilitar a imagem } \\
\text { do enfermeiro na sociedade. }\end{array}$ \\
\hline $\begin{array}{l}\text { Galanis et al., } \\
2021\end{array}$ & $\begin{array}{l}\text { Nurses' burnout and } \\
\text { associated risk factors during } \\
\text { the COVID-19 pandemic: A } \\
\text { systematic review and meta- } \\
\text { analysis. }\end{array}$ & J Adv Nurs & $\begin{array}{l}\text { Examinar o esgotamento dos } \\
\text { enfermeiros e os fatores de } \\
\text { risco associados durante a } \\
\text { pandemia COVID- } 19 \text {. }\end{array}$ & $\begin{array}{l}\text { Os principais fatores de risco que aumentaram o esgotamento } \\
\text { dos enfermeiros foram os seguintes: idade mais jovem, } \\
\text { diminuição do apoio social, baixa disponibilidade da família e } \\
\text { dos colegas para lidar com o surto de COVID-19, aumento da } \\
\text { ameaça percebida de Covid-19, tempo de trabalho mais longo } \\
\text { em áreas de quarentena, trabalho em ambiente de alto risco, } \\
\text { atuação em hospitais com recursos materiais e humanos } \\
\text { inadequados e insuficientes, aumento da carga horária e menor } \\
\text { nível de formação especializada em relação ao COVID-19. } \\
\text { Os enfermeiros experimentam altos níveis de burnout durante } \\
\text { a pandemia de COVID-19, enquanto vários fatores } \\
\text { sociodemográficos, sociais e ocupacionais afetam esse } \\
\text { burnout. }\end{array}$ \\
\hline $\begin{array}{l}\text { Galletta et } \\
\text { al.,2021 }\end{array}$ & $\begin{array}{l}\text { Worries, Preparedness, and } \\
\text { Perceived Impact of Covid- } \\
19 \text { Pandemic on Nurses' } \\
\text { Mental Health }\end{array}$ & $\begin{array}{l}\text { Saúde Mental } \\
\text { Pública. }\end{array}$ & 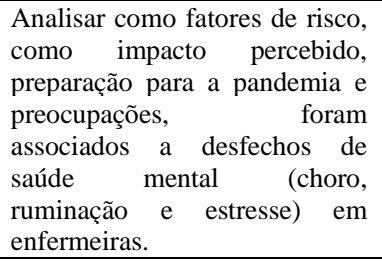 & $\begin{array}{l}\text { Destacou-se que o impacto percebido e as preocupações com } \\
\text { a pandemia afetaram a saúde mental dos enfermeiros e que } \\
\text { podem impactar sua eficácia geral durante a pandemia. }\end{array}$ \\
\hline
\end{tabular}




\begin{tabular}{|c|c|c|c|c|}
\hline $\begin{array}{l}\text { Linares et al., } \\
2021\end{array}$ & $\begin{array}{l}\text { As repercussões da ameaça } \\
\text { percebida do COVID-19 na } \\
\text { saúde mental de enfermeiras } \\
\text { ativamente empregadas. }\end{array}$ & $\begin{array}{l}\text { Revista } \\
\text { Internacional de } \\
\text { Enfermagem } \\
\text { em Saúde } \\
\text { Mental. }\end{array}$ & $\begin{array}{l}\text { Analisar a repercussão da } \\
\text { percepção de ameaça do } \\
\text { COVID-19 na saúde mental de } \\
\text { enfermeiros com vínculo } \\
\text { empregatício, considerando um } \\
\text { diagnóstico de COVID-19, seja } \\
\text { ele próprio ou de alguém } \\
\text { próximo. }\end{array}$ & $\begin{array}{l}\text { A ameaça percebida do COVID-19 foi maior em enfermeiras } \\
\text { com diagnóstico de COVID-19 positivo, naquelas que tiveram } \\
\text { alguém positivo entre amigos e familiares e } \\
\text { mulheres. Também houve uma relação positiva entre o nível } \\
\text { de ameaça percebida e as repercussões em sua saúde mental } \\
\text { (sintomas somáticos, ansiedade, insônia, disfunção social e } \\
\text { depressão).Os resultados deste estudo mostraram ainda que } \\
\text { esta ameaça mediada na relação entre um diagnóstico positivo } \\
\text { e os indicadores de saúde mental estudados, mas era limitada a } \\
\text { sintomas de ansiedade, insônia em enfermeiros com alguém } \\
\text { COVID-19 positivo próximo a eles. }\end{array}$ \\
\hline $\begin{array}{l}\text { Luz et al., } \\
2021\end{array}$ & $\begin{array}{l}\text { Burnout e saúde mental em } \\
\text { tempos de pandemia de } \\
\text { COVID-19: } \\
\text { sistemática com metanálise. }\end{array}$ & $\begin{array}{l}\text { Nursing - São } \\
\text { Paulo. }\end{array}$ & $\begin{array}{l}\text { Identificar os impactos gerados } \\
\text { pela pandemia na saúde mental } \\
\text { dos profissionais enfermeiros. }\end{array}$ & $\begin{array}{l}\text { Cargas horárias exaustivas, más condições de trabalho, } \\
\text { deficiência no dimensionamento de pessoal, poucos recursos } \\
\text { materiais, desvalorização e baixa remuneração. Esses fatores, } \\
\text { associados ao medo de transmitir a doença para familiares e } \\
\text { amigos, o isolamento social e outros aumentam o risco de } \\
\text { desenvolvimento de problemas psicológicos causando efeitos } \\
\text { deletérios à saúde mental. }\end{array}$ \\
\hline $\begin{array}{l}\text { Miranda et } \\
\text { al., } 2021\end{array}$ & $\begin{array}{l}\text { Sofrimento psíquico entre os } \\
\text { profissionais de enfermagem } \\
\text { durante a pandemia da } \\
\text { COVID-19: Scoping Review }\end{array}$ & $\begin{array}{l}\text { Escola Anna } \\
\text { Nery Revista de } \\
\text { Enfermagem. }\end{array}$ & $\begin{array}{l}\text { Mapear sistematicamente a } \\
\text { produção de conhecimento, } \\
\text { com a literatura nacional e } \\
\text { internacional, de situações de } \\
\text { sofrimento psíquico que os } \\
\text { profissionais de enfermagem } \\
\text { vivenciam quando expostos à } \\
\text { pandemia da COVID-19. }\end{array}$ & $\begin{array}{l}\text { As situações de sofrimento psíquico mais relatadas } \\
\text { relacionaram-se à sobrecarga de trabalho, escassez ou ausência } \\
\text { de equipamento de proteção individual, medo de se infectar, } \\
\text { infectar outras pessoas e estar na linha de frente junto a } \\
\text { pacientes com diagnóstico ou suspeita de COVID-19. Os } \\
\text { sinais e sintomas de sofrimentos psíquicos mais encontrados } \\
\text { foram ansiedade, depressão, insônia, estresse, estresse pós- } \\
\text { traumático e medo. }\end{array}$ \\
\hline $\begin{array}{l}\text { Nikeghbal et } \\
\text { al., } 2021\end{array}$ & $\begin{array}{l}\text { Covid-19 Effects on the } \\
\text { Mental Workload and } \\
\text { Quality of Work Life in } \\
\text { Iranian Nurses. }\end{array}$ & $\begin{array}{ll}\text { Ann } & \text { Glob } \\
\text { Health } & \end{array}$ & $\begin{array}{l}\text { Investigar a relação entre a } \\
\text { carga mental e qualidade de } \\
\text { trabalho a vida em enfermeiros } \\
\text { em unidades de terapia } \\
\text { intensiva de Covid-19 } \\
\text { pacientes. }\end{array}$ & $\begin{array}{l}\text { As enfermeiras que cuidam de pacientes com Covid-19 estão } \\
\text { em uma situação mais desfavorável em termos das } \\
\text { características estudadas. Devido ao período de trabalho, esses } \\
\text { enfermeiros apresentaram elevada carga de trabalho e baixa } \\
\text { qualidade de vida no trabalho, ocasionando alterações mentais } \\
\text { e físicas devido longa jornada de trabalho. }\end{array}$ \\
\hline $\begin{array}{l}\text { Ohue et al., } \\
2021\end{array}$ & $\begin{array}{l}\text { Mental health of nurses } \\
\text { involved with COVID-19 } \\
\text { patients in Japan, intention to } \\
\text { resign, and influencing } \\
\text { factors. }\end{array}$ & $\begin{array}{l}\text { Revista: } \\
\text { Medicine } \\
\text { (Baltimore) }\end{array}$ & $\begin{array}{l}\text { Investigar a associação entre } \\
\text { saúde mental (transtorno de } \\
\text { estresse pós-traumático, } \\
\text { depressão, transtorno de } \\
\text { ansiedade e burnout) e intenção } \\
\text { de demitir-se e fatores que } \\
\text { influenciam os enfermeiros } \\
\text { envolvidos com pacientes } \\
\text { COVID-19 na Prefeitura de A } \\
\text { como sujeitos }\end{array}$ & $\begin{array}{l}\text { Entre } 20 \% \text { e } 30 \% \text { dos enfermeiros envolvidos com pacientes } \\
\text { com COVID-19 estão em um estado de alto sofrimento } \\
\text { mental. O aumento do número de pacientes com COVID-19 } \\
\text { foi um fator que afetou a saúde mental e a intenção de } \\
\text { renunciar. Quando o número de pacientes aumentou, os } \\
\text { transtornos de ansiedade e a intenção de renunciar também } \\
\text { aumentaram. Os danos causados por rumores prejudiciais } \\
\text { aumentaram a gravidade de todos os sintomas psiquiátricos. }\end{array}$ \\
\hline $\begin{array}{l}\text { Pereira et al., } \\
2021\end{array}$ & $\begin{array}{l}\text { Os desafios da enfermagem } \\
\text { no enfrentamento a Covid-19 }\end{array}$ & $\begin{array}{l}\text { Brazilian } \\
\text { Journal of } \\
\text { Development. }\end{array}$ & $\begin{array}{l}\text { Argumentar os principais } \\
\text { desafios que a enfermagem } \\
\text { passa a ter na linha de frente do } \\
\text { combate contra o novo } \\
\text { Coronavírus em meio à } \\
\text { sociedade universal. }\end{array}$ & $\begin{array}{l}\text { O impacto do novo Coronavírus trouxe a mobilização e um } \\
\text { desafio mundial para as autoridades, órgãos de vigilância } \\
\text { sanitária e epidemiológicas da área de enfermagem e da } \\
\text { saúde. Observou-se um olhar crítico nas sociedades científicas } \\
\text { na ocasião do enfrentamento dessa pandemia que envolve a } \\
\text { linha de frente dos profissionais em saúde, destacando-se a } \\
\text { enfermagem, para atuarem nos diferentes especialistas em } \\
\text { saúde. }\end{array}$ \\
\hline $\begin{array}{l}\text { Pozo-Herce } \\
\text { et al., } 2021\end{array}$ & $\begin{array}{l}\text { Psychological impact on } \\
\text { nursing professionals at the } \\
\text { Rioja Health Service (Spain) } \\
\text { due to the SARS-CoV-2 } \\
\text { virus. }\end{array}$ & $\begin{array}{l}\text { Jornal } \\
\text { Internacional de } \\
\text { Pesquisa } \\
\text { Ambiental e } \\
\text { Saúde Pública }\end{array}$ & $\begin{array}{l}\text { O objetivo deste estudo foi } \\
\text { conhecer o impacto psicológico } \\
\text { do vírus SARS-CoV-2 nos } \\
\text { profissionais de enfermagem do } \\
\text { Serviço de Saúde de Rioja. }\end{array}$ & $\begin{array}{l}\text { A pandemia COVID-19 teve um impacto psicológico } \\
\text { significativo nos profissionais de saúde, tanto em termos de } \\
\text { estresse, bem-estar emocional quanto no uso de estratégias de } \\
\text { enfrentamento. Em nosso contexto, as profissionais de saúde } \\
\text { do sexo feminino com dependentes, com contrato temporário e } \\
\text { menos experiência de trabalho foram mais afetadas } \\
\text { psicologicamente do que outras. }\end{array}$ \\
\hline $\begin{array}{l}\text { Queiroz et al., } \\
2021\end{array}$ & $\begin{array}{l}\text { O 'NOVO' da COVID-19: } \\
\text { impactos na saúde mental de } \\
\text { profissionais de } \\
\text { enfermagem? }\end{array}$ & $\begin{array}{l}\text { ACTA Paulista } \\
\text { de Enfermagem. }\end{array}$ & $\begin{array}{l}\text { Apreender os impactos na } \\
\text { saúde mental de profissionais } \\
\text { de Enfermagem face às } \\
\text { interações com o 'novo' da } \\
\text { pandemia da Covid-19. }\end{array}$ & $\begin{array}{l}\text { O discurso coletivo evidenciou que a saúde mental de } \\
\text { profissionais de Enfermagem foi afetada pelas interações com } \\
\text { o 'novo' com elaboração de significados atribuídos à } \\
\text { pandemia; interações com o cuidado de Enfermagem } \\
\text { relacionadas com os atendimentos aos pacientes; e interações } \\
\text { com o trabalho demarcadas pelas relações profissionais e } \\
\text { institucionais. }\end{array}$ \\
\hline $\begin{array}{l}\text { Santos et al., } \\
2021\end{array}$ & $\begin{array}{l}\text { Depressão e ansiedade em } \\
\text { profissionais de enfermagem } \\
\text { durante a pandemia da covid- } \\
19 .\end{array}$ & $\begin{array}{lr}\text { Escola } & \text { Anna } \\
\text { Nery. } & \text { Revista } \\
\text { de Enfermagem. }\end{array}$ & $\begin{array}{l}\text { Analisar a prevalência de } \\
\text { sintomas depressão, ansiedade } \\
\text { e fatores associados em } \\
\text { profissionais da equipe de } \\
\text { enfermagem durante } \\
\text { pandemia da Covid-19. }\end{array}$ & $\begin{array}{l}\text { A ocorrência de sintomas sugestivos de transtornos mentais } \\
\text { (ansiedade e depressão) estava relacionada à profissionais de } \\
\text { enfermagem do sexo feminino, cor ou raça parda, com renda } \\
\text { mensal inferior a } 5 \text { salários mínimos que trabalhavam no setor } \\
\text { privado, ter sintomas de Síndrome de Burnout e morar com os } \\
\text { pais. As ocorrências foram mais acentuadas quando os } \\
\text { serviços não apresentavam condições adequadas de trabalho, } \\
\text { em especial para o enfrentamento da pandemia de Covid-19. }\end{array}$ \\
\hline $\begin{array}{l}\text { Sánchez- } \\
\text { Sánchez et } \\
\text { al., } 2021\end{array}$ & $\begin{array}{lr}\text { IMPACTO DA PANDEMIA } \\
\text { DO COVID-19 NA SAÚDE } \\
\text { MENTAL } \\
\text { ENFERMEIRAS } & \text { EE } \\
\end{array}$ & $\begin{array}{l}\text { Int. J. } \\
\text { Environ. Res. } \\
\text { Public Health. }\end{array}$ & $\begin{array}{l}\text { Determinar os sintomas de } \\
\text { depressão e / ou ansiedade } \\
\text { entre enfermeiras e ANCTs } \\
\text { durante os períodos conhecidos }\end{array}$ & $\begin{array}{l}\text { A pandemia COVID-19 teve um impacto negativo na saúde } \\
\text { mental dos profissionais de saúde, especialmente enfermeiros } \\
\text { e técnicos auxiliares de enfermagem (ANCTs), devido ao } \\
\text { aumento da carga de cuidados ou ao medo de enfrentar uma }\end{array}$ \\
\hline
\end{tabular}




\begin{tabular}{|c|c|c|c|c|}
\hline & $\begin{array}{l}\text { TÉCNICOS AUXILIARES } \\
\text { DE ENFERMAGEM - UMA } \\
\text { PESQUISA } \quad \text { ON-LINE } \\
\text { VOLUNTÁRIA }\end{array}$ & & $\begin{array}{lrr}\text { como primeira onda } & \text { (março- } \\
\text { junho) e segunda } & \text { onda } \\
\text { (setembro-novembro) } & \text { da } \\
\text { pandemia COVID-19 } & \text { na } \\
\text { Espanha. } & & \end{array}$ & $\begin{array}{l}\text { situação nova ou altamente estressante. } \\
\text { Sintomas de ansiedade e / ou depressão estiveram presentes } \\
\text { nesses profissionais durante a pandemia, sendo maiores no } \\
\text { primeiro período do que no segundo, devido à falta de } \\
\text { conhecimento, falta de recursos e incerteza no início da } \\
\text { pandemia. }\end{array}$ \\
\hline $\begin{array}{l}\text { Sharma et al., } \\
2021\end{array}$ & 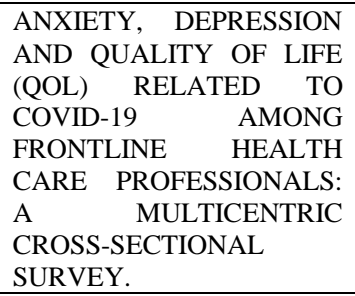 & $\begin{array}{l}\text { J Family Med } \\
\text { Prim Care. }\end{array}$ & $\begin{array}{l}\text { Identificar ansiedade, depressão } \\
\text { e qualidade de vida e seus } \\
\text { preditores entre enfermeiros } \\
\text { que estão ativamente } \\
\text { envolvidos no cuidado de } \\
\text { pacientes com COVID-19. }\end{array}$ & $\begin{array}{l}\text { Os enfermeiros estão prestando seus serviços além das } \\
\text { fronteiras para que possamos superar os tempos difíceis da } \\
\text { pandemia COVID-19. Embora menos, mas ainda assim, as } \\
\text { enfermeiras sofrem de ansiedade e depressão, que precisam } \\
\text { ser tratadas para proteger e melhorar seu bem-estar mental. }\end{array}$ \\
\hline $\begin{array}{l}\text { Souza et al., } \\
2021\end{array}$ & $\begin{array}{l}\text { Trabalho da enfermagem na } \\
\text { pandemia do COVID-19 e } \\
\text { repercussões na saúde mental } \\
\text { dos trabalhadores }\end{array}$ & $\begin{array}{l}\text { Revista Gaúcha } \\
\text { de Enfermagem. }\end{array}$ & $\begin{array}{l}\text { Refletir sobre o contexto de } \\
\text { trabalho dos profissionais de } \\
\text { enfermagem na pandemia do } \\
\text { COVID-19 e as repercussões } \\
\text { para a saúde mental desses } \\
\text { profissionais. }\end{array}$ & $\begin{array}{l}\text { A pandemia COVID-19 explicitou os reflexos da precariedade } \\
\text { no setor saúde. Foi evidenciado o sofrimento psíquico dos } \\
\text { trabalhadores de enfermagem devido à escassez de } \\
\text { equipamentos de proteção individual, à fragilidade na } \\
\text { descrição dos protocolos e dos fluxos para o controle efetivo } \\
\text { de infecções, à longa jornada de trabalho, à formação } \\
\text { profissional inadequada para cenário de crise e incerteza em } \\
\text { relação às medidas terapêuticas. }\end{array}$ \\
\hline $\begin{array}{l}\text { Souza et al., } \\
2021\end{array}$ & $\begin{array}{l}\text { Contexto do trabalho da } \\
\text { enfermagem na pandemia de } \\
\text { Covid-19 e repercussões na } \\
\text { saúde mental dos } \\
\text { trabalhadores. }\end{array}$ & $\begin{array}{l}\text { Revista Gaúcha } \\
\text { de Enfermagem. }\end{array}$ & $\begin{array}{l}\text { Refletir sobre o contexto de } \\
\text { trabalho dos profissionais de } \\
\text { enfermagem na pandemia } \\
\text { Covid-19 e as repercussões } \\
\text { para a saúde mental desses } \\
\text { profissionais. }\end{array}$ & $\begin{array}{l}\text { A pandemia de Covid-19 explicitou os reflexos da } \\
\text { precariedade no setor saúde. Evidenciou-seo sofrimento } \\
\text { psíquico dos trabalhadores de enfermagem devido à escassez } \\
\text { de equipamentos de proteção individual, à fragilidade na } \\
\text { descrição dos protocolos e aos fluxos para o hospital. controle } \\
\text { eficaz de infecções, jornada de trabalho prolongada, formação } \\
\text { profissional inadequada para o cenário de crise e incertezas em } \\
\text { relação às medidas terapêuticas. }\end{array}$ \\
\hline $\begin{array}{l}\text { Sharma et al., } \\
2021\end{array}$ & $\begin{array}{l}\text { Anxiety, depression and } \\
\text { quality of life (QOL) related } \\
\text { to COVID-19 among } \\
\text { frontline health care } \\
\text { professionals: A multicentric } \\
\text { cross-sectional survey. }\end{array}$ & $\begin{array}{l}\text { J Family Med } \\
\text { Prim Care }\end{array}$ & $\begin{array}{l}\text { Identificar ansiedade, depressão } \\
\text { e qualidade de vida e seus } \\
\text { preditores entre enfermeiros } \\
\text { que estão ativamente } \\
\text { envolvidos no cuidado de } \\
\text { pacientes com COVID-19. }\end{array}$ & $\begin{array}{l}\text { Os enfermeiros estão prestando seus serviços além das } \\
\text { fronteiras para que possamos superar os tempos difíceis da } \\
\text { pandemia COVID-19. Embora menos, mas ainda assim, as } \\
\text { enfermeiras sofrem de ansiedade e depressão, que precisam } \\
\text { ser tratadas para proteger e melhorar seu bem-estar mental. }\end{array}$ \\
\hline $\begin{array}{l}\text { Varghese et } \\
\text { al., } 2021\end{array}$ & $\begin{array}{l}\text { Decline in the mental health } \\
\text { of nurses across the globe } \\
\text { during COVID-19: A } \\
\text { systematic review and meta- } \\
\text { analysis. }\end{array}$ & $\begin{array}{l}\text { Revista: J Glob } \\
\text { Health }\end{array}$ & $\begin{array}{l}\text { Explorar a prevalência e os } \\
\text { determinantes dos resultados de } \\
\text { saúde mental (ansiedade, } \\
\text { estresse, depressão,Perturbação } \\
\text { de stresse pós- } \\
\text { traumático(PTSD), insônia) } \\
\text { entreenfermeiras em todo o } \\
\text { mundo devido ao COVID-19. }\end{array}$ & $\begin{array}{l}\text { Os resultados do estudo destacaram uma proporção maior de } \\
\text { resultados ruins de saúde mental, ou seja, ansiedade, estresse, } \\
\text { depressão, PTSD e insônia entre enfermeiras de diferentes } \\
\text { partes do mundo. Os maus resultados de saúde mental entre os } \\
\text { enfermeiros justificam a necessidade de implementar } \\
\text { intervenções psicológicas proativas para impedir o colapso dos } \\
\text { sistemas de saúde na resposta à pandemia e, em particular, } \\
\text { todos os esforços possíveis devem ser realizados para mitigar } \\
\text { os fatores de risco. }\end{array}$ \\
\hline $\begin{array}{lr}\text { Alves } & \text { e } \\
\text { Ferreira. } 2020\end{array}$ & $\begin{array}{lll}\text { Covid-19: } & \text { Reflexão } & \text { da } \\
\text { atuação do enfermeiro } & \text { no } \\
\text { combate ao desconhecido } & \end{array}$ & $\begin{array}{l}\text { Enfermagem } \\
\text { em Foco }\end{array}$ & \begin{tabular}{l}
\multicolumn{3}{l}{ Refletir sobre as consequências } \\
da atuação do enfermeiro \\
perante o surgimento da \\
COVID-19.
\end{tabular} & $\begin{array}{l}\text { Torna-se evidente que o novo coronavírus está sendo o maior } \\
\text { desafio enfrentado pelo mundo, com uma rápida } \\
\text { disseminação. O uso de máscaras, uma boa higiene das mãos e } \\
\text { a descontaminação da superfície são fundamentais para a } \\
\text { segurança. Entretanto, há uma limitação da quantidade de } \\
\text { equipamentos de proteção individual, somado a sobrecarga } \\
\text { emocional dos enfermeiros e as péssimas condições de } \\
\text { trabalho que já os acompanham, eles que estão na linha de } \\
\text { frente no combate. Em meio ao desconhecido, uma estratégia } \\
\text { especial para a atuação da enfermagem é necessária, } \\
\text { protegendo-os. }\end{array}$ \\
\hline $\begin{array}{l}\text { Clementino et } \\
\text { al., } 2020\end{array}$ & $\begin{array}{l}\text { Enfermagem na Atenção às } \\
\text { pessoas com Covid-19: } \\
\text { Desafios na atuação do } \\
\text { Sistema COFEN/CORENs }\end{array}$ & $\begin{array}{ll}\text { Texto } & \mathrm{e} \\
\text { Contexto } & \\
\text { Enfermagem } & \end{array}$ & $\begin{array}{l}\text { Analisar os desafios dos } \\
\text { Conselhos Federal e Regionais } \\
\text { de Enfermagem perante a } \\
\text { atuação da enfermagem na } \\
\text { atenção às pessoas com } \\
\text { COVID-19. }\end{array}$ & $\begin{array}{l}\text { A maioria das notícias veiculadas pelo Conselho Federal de } \\
\text { Enfermagem citava o suporte e apoio aos profissionais, e, } \\
\text { pelos Conselhos Regionais de Enfermagem entre as unidades } \\
\text { incluídas, destacamse a fiscalização de serviços de saúde e } \\
\text { criação de força tarefa. Os achados foram organizados em } \\
\text { quatro categorias: O profissional de enfermagem na pandemia: } \\
\text { a luta contra o inimigo invisível; Condições de trabalho no } \\
\text { cuidado a pessoas com COVID-19: entraves e desafios; } \\
\text { Desvalorização profissional x responsabilidade técnica: } \\
\text { cenário da linha de frente; Saúde mental do profissional de } \\
\text { enfermagem: convivendo com o medo e a incerteza. }\end{array}$ \\
\hline $\begin{array}{l}\text { Dal'Bosco et } \\
\text { al., } 2020\end{array}$ & $\begin{array}{l}\text { A saúde mental da } \\
\text { enfermagem no } \\
\text { enfrentamento da COVID-19 } \\
\text { em um hospital universitário } \\
\text { regional. }\end{array}$ & $\begin{array}{l}\text { REBEn } \\
\text { Revista } \\
\text { Brasileira de } \\
\text { Enfermagem }\end{array}$ & $\begin{array}{l}\text { Identificar a prevalência e os } \\
\text { fatores associados à ansiedade } \\
\text { e depressão em profissionais de } \\
\text { enfermagem que atuam no } \\
\text { enfrentamento do COVID-19 } \\
\text { em um hospital universitário. }\end{array}$ & $\begin{array}{l}\text { Os resultados evidenciarem aspectos importantes do processo } \\
\text { de trabalho da enfermagem diante da referida pandemia e de } \\
\text { sinais de ansiedade e depressão, indicando um sofrimento } \\
\text { psíquico além daquele já intrínseco da profissão. }\end{array}$ \\
\hline $\begin{array}{l}\text { Moreira e } \\
\text { Lucca, } 2020\end{array}$ & $\begin{array}{l}\text { Apoio psicossocial e saúde } \\
\text { mental dos profissionais de }\end{array}$ & \begin{tabular}{l}
\multicolumn{3}{l}{$\begin{array}{l}\text { Enfermagem } \\
\text { em }\end{array} \quad$ Foco. } \\
\end{tabular} & $\begin{array}{l}\text { Descrever e discutir a atuação } \\
\text { dos profissionais } \quad \text { de }\end{array}$ & $\begin{array}{l}\text { Os profissionais de enfermagem estão na linha de frente no } \\
\text { combate ao COVID-19 e expostos a maior risco de }\end{array}$ \\
\hline
\end{tabular}




\begin{tabular}{|c|c|c|c|c|}
\hline & $\begin{array}{l}\text { enfermagem no combate ao } \\
\text { COVID-19. }\end{array}$ & $\begin{array}{l}\text { Revista Oficial } \\
\text { do Conselho } \\
\text { Federal de } \\
\text { Enfermagem. }\end{array}$ & $\begin{array}{l}\text { enfermagem, sua exposição aos } \\
\text { fatores de risco no trabalho e a } \\
\text { importância do apoio } \\
\text { psicossocial na } \\
\text { COVID-19. }\end{array}$ & $\begin{array}{l}\text { contaminação devido à escassez de recursos, como a falta de } \\
\text { equipamentos de proteção individual. Os afastamentos dos } \\
\text { colegas contaminados, as altas demandas, a escassez de } \\
\text { materiais, o medo de ser contaminado e a falta de apoio } \\
\text { psicossocial sobrecarregam esses profissionais e causa estresse } \\
\text { e pode desencadear esgotamento físico e psíquico. }\end{array}$ \\
\hline $\begin{array}{l}\text { Oliveira et } \\
\text { al.. } 2020\end{array}$ & $\begin{array}{lr}\text { Saúde mental no progresso } \\
\begin{array}{lr}\text { da pandemia de COVID-19: } \\
\text { concepções } & \text { dos } \\
\text { trabalhadores da } & \text { atenção } \\
\text { primária à saúde } & \end{array}\end{array}$ & $\begin{array}{l}\text { Research, } \\
\text { Society and } \\
\text { Development. }\end{array}$ & $\begin{array}{l}\text { Compreender as percepções de } \\
\text { trabalhadores da equipe Saúde } \\
\text { da família sobre as implicações } \\
\text { da pandemia da COVID-19nas } \\
\text { demandas de saúde mental no } \\
\text { contexto da Atenção Primária, } \\
\text { com vistas a contribuir com } \\
\text { estudos ainda escassos sobre a } \\
\text { temática. }\end{array}$ & $\begin{array}{l}\text { Resultadose discussão: apresentam categorias advindas dos } \\
\text { discursos de nove trabalhadoras, duas de nível superior e sete } \\
\text { de nível médio. Emergiu-se a partir dos discursos, um } \\
\text { conjunto de implicações da pandemia do novo Coronavírus } \\
\text { nas demandas de saúde mental do território de atuação da } \\
\text { Atenção Primária, decorrentes das estratégias de } \\
\text { distanciamento e isolamento social, as quais atingiram } \\
\text { usuários e profissionais, aumentando a incidência dos casos de } \\
\text { sofrimento psíquico e comprometendo a qualidade da oferta de } \\
\text { ações de cuidado nesse espaço. }\end{array}$ \\
\hline $\begin{array}{l}\text { Prado et al., } \\
2020\end{array}$ & $\begin{array}{l}\text { A saúde mental dos } \\
\text { profissionais de saúde frente } \\
\text { à pandemia do Covid-19: } \\
\text { uma revisão integrativa. }\end{array}$ & $\begin{array}{l}\text { Revista } \\
\text { Eletrônica } \\
\text { Acervo Saúde }\end{array}$ & $\begin{array}{l}\text { Conhecer a situação da saúde } \\
\text { mental dos profissionais da } \\
\text { área da saúde da linha de frente } \\
\text { na pandemia do COVID-19, e } \\
\text { quais consequências para os } \\
\text { serviços de saúde. }\end{array}$ & $\begin{array}{l}\text { Percebeu-se a fragilidade na saúde mental do trabalhador da } \\
\text { saúde, dentro de incertezas do futuro e da cura do vírus } \\
\text { COVID-19. Dessa forma, percebe-se altos índices de } \\
\text { ansiedade, estresse, depressão, medo, angústia e sono alterado, } \\
\text { doenças e muitas vezes esse profissional não procura ajuda } \\
\text { para si mesmo }\end{array}$ \\
\hline $\begin{array}{l}\text { Ramos- } \\
\text { Toescher et } \\
\text { al., } 2020\end{array}$ & $\begin{array}{lll}\text { Saúde } & \text { mental } & \text { de } \\
\text { profissionais } & \text { de enfermagem } \\
\text { durante a } & \text { pandemia } & \text { de } \\
\text { COVID-19: } & \text { recursos } & \text { de } \\
\text { apoio. } & & \end{array}$ & $\begin{array}{lr}\text { Escola } & \text { Anna } \\
\text { Nery. } & \text { Revista } \\
\text { de Enfermagem. }\end{array}$ & $\begin{array}{l}\text { Refletir sobre as implicações da } \\
\text { pandemia de coronavírus na } \\
\text { saúde mental dos profissionais } \\
\text { de enfermagem e os principais } \\
\text { recursos de apoio em } \\
\text { desenvolvimento. }\end{array}$ & $\begin{array}{l}\text { em resposta à pandemia, uma crise em saúde mental pode } \\
\text { estar a ocorrer entre os profissionais de enfermagem. Por } \\
\text { estarem, diretamente, ligados ao atendimento de casos do novo } \\
\text { coronavírus, experienciam situações estressoras, adicionais } \\
\text { àquelas já vivenciadas nos serviços de saúde, incluindo } \\
\text { preocupações, medo e insegurança com a saúde de si e da } \\
\text { população. Como resultado, foi possível refletir acerca das } \\
\text { principais implicações da pandemia para os profissionais de } \\
\text { enfermagem e os principais recursos de apoio em } \\
\text { desenvolvimento, especialmente relacionados a identificação e } \\
\text { manejo de situações estressantes. }\end{array}$ \\
\hline $\begin{array}{l}\text { Humerez, Ohl } \\
\text { e Silva, } 2020\end{array}$ & $\begin{array}{l}\text { Saúde mental dos } \\
\text { profissionais de enfermagem } \\
\text { no Brasil no contexto da } \\
\text { pandemia Covid-19: ação do } \\
\text { Conselho Federal de } \\
\text { Enfermagem }\end{array}$ & $\begin{array}{l}\text { Revista } \\
\text { Cogitare } \\
\text { Enfermagem. }\end{array}$ & $\begin{array}{l}\text { Relatar sobre a saúde mental de } \\
\text { dois profissionais brasileiros de } \\
\text { doenças no contexto da } \\
\text { pandemia de COVID-19. }\end{array}$ & $\begin{array}{l}\text { Diante dessa realidade, os profissionais da enfermagem fazem } \\
\text { parte de um dos grupos mais afetados, expostos ao risco de } \\
\text { contágio e da dor emocional que afeta consideravelmente a } \\
\text { saúde mental. Assim, o Conselho Federal de Enfermagem } \\
\text { determinou à Comissão Nacional de Enfermagem em Saúde } \\
\text { Mental para efetivar atendimento a esses profissionais que se } \\
\text { encontram na linha de frente na atuação da pandemia. }\end{array}$ \\
\hline $\begin{array}{l}\text { Luz et al., } \\
2020\end{array}$ & $\begin{array}{lr}\text { REPERCUSSÕES } & \text { DA } \\
\text { COVID-19 NA SAÚDE } \\
\text { MENTAL } & \text { DOS } \\
\text { TRABALHADORES } & \text { DE } \\
\text { ENFERMAGEM } & \end{array}$ & $\begin{array}{l}\text { Revista de } \\
\text { Enfermagem do } \\
\text { Centro-Oeste } \\
\text { Mineiro. }\end{array}$ & $\begin{array}{l}\text { Refletir acerca das repercussões } \\
\text { da Covid-19 na saúde mental } \\
\text { dos trabalhadores de } \\
\text { enfermagem. }\end{array}$ & $\begin{array}{l}\text { O dimensionamento de } \\
\text { recursos humanos } \\
\text { insuficiente, a complexidade assistencial, o aumento da carga } \\
\text { de trabalho, o medo de contaminação na utilização dos EPIs e } \\
\text { as condições insalubres dos serviços de saúde, o estresse } \\
\text { ocupacional, a síndrome de Burnout, os distúrbios psíquicos } \\
\text { menores e o sofrimento moral são situações que ocasionaram, } \\
\text { nesse período da pandemia, o adoecimento físico e psíquico } \\
\text { dos profissionais de enfermagem. }\end{array}$ \\
\hline $\begin{array}{l}\text { Nabuco, } \\
\text { Oliveira e } \\
\text { Afonso, } 2020\end{array}$ & $\begin{array}{l}\text { O IMPACTO DA } \\
\text { PANDEMIA PELA COVID- } \\
\text { 19 NA SAÚDE MENTAL } \\
\text { QUAL É O PAPEL DA } \\
\text { ATENÇÃO PRIMÁRIA À } \\
\text { SAÚDE? }\end{array}$ & $\begin{array}{l}\text { Rev Bras Med } \\
\text { Fam } \\
\text { Comunidade } \\
\text { [Internet] }\end{array}$ & $\begin{array}{l}\text { Apresentar uma proposta para a } \\
\text { atuação das equipes de Atenção } \\
\text { Primária no enfrentamento ao } \\
\text { adoecimento } \quad \text { mental } \\
\text { relacionado à pandemia. }\end{array}$ & $\begin{array}{l}\text { Os principais fatores de risco para adoecimento mental } \\
\text { identificados incluem: vulnerabilidade social, contrair a } \\
\text { doença ou conviver com alguém infectado, existência de } \\
\text { transtorno mental prévio, ser idoso e ser profissional de saúde. } \\
\text { O isolamento físico e o excesso de informações nem sempre } \\
\text { confiáveis somam estressores à crise. As especificidades do } \\
\text { luto durante a pandemia também aumentam o risco de lutos } \\
\text { complicados. No contexto brasileiro, há ainda a crise político- } \\
\text { institucional aumentando a ansiedade e insegurança da } \\
\text { população. Propõe-se que a Atenção Primária à Saúde, com } \\
\text { suas características e atributos, deve: identificar as famílias } \\
\text { com risco aumentado para adoecimento mental; articular } \\
\text { intersetorialmente para que as demandas dos mais vulneráveis } \\
\text { sejam atendidas; orientar a população sobre como minimizar } \\
\text { os fatores geradores de ansiedade; apoiar as famílias para } \\
\text { possibilitar o processo de luto }\end{array}$ \\
\hline $\begin{array}{l}\text { Santos et al., } \\
2020 \text {. }\end{array}$ & $\begin{array}{l}\text { O impacto da Covid-19 na } \\
\text { saúde mental dos } \\
\text { profissionais de saúde: } \\
\text { Revisão Integrativa. }\end{array}$ & $\begin{array}{l}\text { Research, } \\
\text { Society and } \\
\text { Development. }\end{array}$ & $\begin{array}{l}\text { Avaliar, com base na literatura } \\
\text { pertinente, a saúde mental dos } \\
\text { trabalhadores da saúde na } \\
\text { pandemia de COVID- } 19 .\end{array}$ & $\begin{array}{l}\text { O processo de cuidado direto de pacientes com coronavírus, a } \\
\text { alta exposição ocupacional e disponibilidade inadequada } \\
\text { equipamentos de proteção individual (EPI) geram quadros que } \\
\text { comprometem a saúde mental dos profissionais da linha de } \\
\text { frente nos serviços de saúde,tais como ansiedade, estresse, } \\
\text { insônia e depressão. }\end{array}$ \\
\hline $\begin{array}{l}\text { Moreira e } \\
\text { Lucca, } 2020\end{array}$ & $\begin{array}{lr}\text { APOIO PSICOSSOCIAL E } \\
\text { SAÚDE MENTAL } & \text { DOS } \\
\text { PROFISSIONAIS } & \text { DE } \\
\text { ENFERMAGEM } & \text { NO } \\
\text { COMBATE AO COVID-19 }\end{array}$ & $\begin{array}{l}\text { Enfermagem } \\
\text { em Foco. }\end{array}$ & $\begin{array}{l}\text { Descrever e discutir a atuação } \\
\text { dos profissionais de } \\
\text { enfermagem, sua exposição aos } \\
\text { fatores de risco no trabalho e a } \\
\text { importância do apoio }\end{array}$ & $\begin{array}{l}\text { Os profissionais de enfermagem estão na linha de frente no } \\
\text { combate ao CODIV- } 19 \text { e expostos a maior risco de } \\
\text { contaminação devido à escassez de recursos, como a falta de } \\
\text { equipamentos de proteção individual. Os afastamentos dos } \\
\text { colegas contaminados, as altas demandas, a escassez de }\end{array}$ \\
\hline
\end{tabular}




\begin{tabular}{|c|c|c|c|c|}
\hline & & & $\begin{array}{l}\text { psicossocial na pandemia do } \\
\text { COVID-19. }\end{array}$ & $\begin{array}{l}\text { materiais, o medo de ser contaminado e a falta de apoio } \\
\text { psicossocial sobrecarregam esses profissionais e causa estresse } \\
\text { e pode desencadear esgotamento físico e psíquico. }\end{array}$ \\
\hline $\begin{array}{l}\text { Santana et al., } \\
2020\end{array}$ & $\begin{array}{l}\text { SEGURANÇA DOS } \\
\text { PROFISSIONAIS DE SAÚDE } \\
\text { NO ENFRENTAMENTO DO } \\
\text { NOVO CORONAVÍRUS NO } \\
\text { BRASIL }\end{array}$ & $\begin{array}{l}\text { Escola Anna } \\
\text { Nery. }\end{array}$ & $\begin{array}{l}\text { Apresentar o número de } \\
\text { profissionais de saúde } \\
\text { acometidos pela COVID-19 no } \\
\text { Brasil, identificar algumas } \\
\text { medidas de controle para } \\
\text { redução da vulnerabilidade e as } \\
\text { repercussões sobre a saúde } \\
\text { desses profissionais no } \\
\text { enfrentamento da pandemia } \\
\text { COVID-19. }\end{array}$ & $\begin{array}{l}\text { Os profissionais de enfermagem é o grupo que mais sofreram } \\
\text { repercussões na saúde mental com implicações psíquicas, } \\
\text { transtornos psicológicos e psiquiátricos, isso ocorreu devido a } \\
\text { sobrecarga de trabalho, a escassez dos EPIs, as condições } \\
\text { precárias no trabalho, o isolamento social, o estresse e o medo } \\
\text { da contaminação. }\end{array}$ \\
\hline $\begin{array}{l}\text { Schmidt et } \\
\text { al., } 2020\end{array}$ & $\begin{array}{l}\text { SAÚDE MENTAL E } \\
\text { INTERVENÇÕES } \\
\text { PSICOLÓGICAS DIANTE } \\
\text { DA PANDEMIA DO NOVO } \\
\text { CORONAVÍRUS (COVID-19) }\end{array}$ & $\begin{array}{l}\text { Estudos de } \\
\text { Psicologia } \\
\text { (Campinas) }\end{array}$ & $\begin{array}{l}\text { Sistematizar conhecimentos } \\
\text { sobre implicações na saúde } \\
\text { mental e intervenções } \\
\text { psicológicas diante da } \\
\text { pandemia do novo coronavírus }\end{array}$ & $\begin{array}{l}\text { Apresentam-se resultados sobre implicações da pandemia na } \\
\text { saúde mental, identificação de grupos prioritários e } \\
\text { orientações sobre intervenções psicológicas, considerando } \\
\text { particularidades da população geral e dos profissionais da } \\
\text { saúde. Por fim, discutem-se potencialidades e desafios para a } \\
\text { prática dos psicólogos no contexto brasileiro durante a } \\
\text { pandemia }\end{array}$ \\
\hline
\end{tabular}

Fonte: Autores (2021).

Os trabalhadores da enfermagem pressionados com essa situação apresentam altos níveis de ansiedade, acrescidos do risco de adoecer, provocando severos problemas de saúde mental e aumentando os casos da Síndrome de Burnout, além de gerar ansiedade, depressão e estresse associado (Humerez, Ohl \& Silva, 2020).

O Quadro 3 representa os subtítulos utilizados na discussão dos artigos selecionados para facilitar o entendimento e a explanação do conteúdo abaixo. O foco do estudo envolveu três subtemas: A enfermagem no contexto da pandemia do Covid19; Impactos do vírus na saúde mental dos profissionais de enfermagem durante a pandemia do Covid-19 e os Recursos de apoio dos profissionais de enfermagem no enfrentamento ao Covid-19.

Quadro 3: Distribuição dos artigos em repercussões do estudo e identificação dos artigos por autores.

\begin{tabular}{|c|c|}
\hline REPERCUSSÕES DO ESTUDO & IDENTIFICAÇÃO DOS ARTIGOS POR AUTORES \\
\hline $\begin{array}{l}\text { A enfermagem no contexto da pandemia do Covid-19 } \\
\text { - Medo da autocontaminação; } \\
\text { - Insalubridade; } \\
\text { - Escassez de EPIs; } \\
\text { - Isolamento social; } \\
\text { - Desvalorização; } \\
\text { - Sobrecarga na jornada de trabalho; } \\
\text { - Condições precárias no ambiente de trabalho; } \\
\text { - Vulnerabilidade social. }\end{array}$ & $\begin{array}{l}\text { (Luz et al., 2021); (Miranda et al., 2021); (Clementino et al., } \\
\text { 2020); (Moreira; De Lucca; 2020); (Barbosa et al., 2020); } \\
\text { (Souza et al., 2021); (Santos et al., 2021); (Nikeghbal et al., } \\
\text { 2021); (Santos et al., 2020); (Duarte; Silva; Bagatini; 2021); } \\
\text { (Sánchez-Sánchez et al., 2021); (Luz et al., 2020); (Santana et } \\
\text { al., 2020); (Coren-ES, 2021); (Pereira et al., 2021); (David et } \\
\text { al., 2021); (Coren-BA, 2020); (Nabuco; Oliveira e Afonso. } \\
\text { 2020). }\end{array}$ \\
\hline $\begin{array}{l}\text { Impactos do vírus na saúde mental dos profissionais de } \\
\text { enfermagem durante a pandemia do Covid-19 } \\
\text { - Depressão; } \\
\text { - Ansiedade; } \\
\text { - Síndrome de Burnout; } \\
\text { - Estresse pós-traumático; } \\
\text { - Medo; } \\
\text { - Insônia; } \\
\text { - Angústia; } \\
\text { - Infodemia. }\end{array}$ & $\begin{array}{l}\text { (Miranda et al., 2021); (Clementino et al., 2020); (Ramos- } \\
\text { Toescher et al., 2020); (Dal'Bosco et al., 2020); (Santos et al., } \\
2021 \text { (Santos et al., 2020); (Crowe et al., 2021); (Duarte; Silva; } \\
\text { Bagatini; 2021); (Galleta et al., 2021); (Linares et al., 2021); } \\
\text { (Sánchez-Sánchez et al., 2021); (Alencastro; Melo, 2021); } \\
\text { (Galanis et al. 2021); (Luz et al., 2020); (Santana et al., 2020); } \\
\text { (Sharma et al., 2021). }\end{array}$ \\
\hline $\begin{array}{l}\text { Recursos de apoio dos profissionais de enfermagem no } \\
\text { enfrentamento ao Covid-19 } \\
\text { - Bem-estar psicossocial; } \\
\text { - Autocuidado; } \\
\text { - Apoio psicossocial; } \\
\text { - Sono regular; } \\
\text { - Pratica de atividades físicas; } \\
\text { - Manter contato com os familiares e amigos. }\end{array}$ & $\begin{array}{l}\text { (Ramos-Toescher et al., 2020); (Brasil, } \\
\text { ado et al., 2020). }\end{array}$ \\
\hline
\end{tabular}




\section{Categoria 1: A Enfermagem no contexto da pandemia do Covid-19}

Diante da grave crise sanitária provocada pela pandemia do coronavírus (Covid-19), os olhares em todo o mundo se voltaram à ciência e ao trabalho dos profissionais da saúde na intensa luta contra a doença e em favor da vida, em especial ao trabalho dos profissionais de enfermagem (Coren-ES, 2021), migrando de um status de desvalorização ao de herói (Queiroz et al., 2021). O reconhecimento da atuação desses autores nesse momento de crise pandêmica foi um evento marcante e histórico, e ao mesmo tempo escancarou a desvalorização em respeito ao piso salarial imposto pelos governantes e empregadores para a contratação de profissionais da saúde para os hospitais de campanha destinados à Covid-19 (Clementino et al., 2020).

Nenhum outro profissional realiza o serviço exclusivo dos enfermeiros, prestando serviços 24 horas por dia à pacientes com maior vulnerabilidade para se infectarem (Varghese et al., 2021), sendo impossível igualá-los, tal complexidade tornou-se ainda mais intensa com o advento da pandemia da COVID-19 (Miranda et al., 2021). Os profissionais da enfermagem e da saúde de uma forma geral precisam estar instrumentalizados, assim como os gestores e os coordenadores precisam perpetuar um planejamento institucional que ofereça capacitações contínuas, para lidar com a potencialidade que o contexto atual de pandemia oferece (Pereira et al., 2021).

A pandemia provocou implicação psicológica imensas aos profissionais de saúde devido a uma combinação de fatores estressantes no local de trabalho e medos pessoais (Sánchez-sánches et al., 2021). Os velhos desafios se juntaram aos novos, diante a pandemia, deixando em evidência a importância dos enfermeiros em desempenhar seu papel no cuidado à pessoas doentes ou com suspeita de infecção por COVID-19. O cuidado exercido por esses profissionais tem sido ressaltado em termos da necessária competência técnica e humana para o cuidado ágil e seguro (David et al., 2021). Porém, esses profissionais estão expostos a diversos perigos como a contaminação com o novo vírus e outros patógenos, que mesmo diante de uma pandemia não deixaram de existir, necessitando de medidas protetivas.

Como a transmissão do SARS-COV-2 acontece de uma pessoa doente para outra, através de gotículas de saliva, os profissionais que atuam junto à pacientes com a doença, devem fazer uso adequado de equipamento de proteção individual (EPIs), tais como: máscaras cirúrgicas ou máscaras de proteção respiratórias, capote ou avental, luvas, protetor ocular ou protetor de face e gorro, os quais são essenciais para preservar o trabalhador de possível contágio (Coren- BA, 2020).

\section{Categoria 2:Impactos na saúde mental dos profissionais de enfermagem durante a pandemia da Covid-19}

A pandemia da Covid-19 trouxe sérios problemas para o sistema de saúde, causando grandes impactos não apenas nas questões financeiras, mas também na saúde física e mental dos profissionais de saúde que estão na linha de frente ao combate do coronavírus, principalmente dos profissionais de enfermagem. Trabalhar em meio a uma pandemia exige dos profissionais e dos serviços uma estrutura consistente capaz de comandar e controlar a tomada de decisões e as informações, permitindo que estes possam atravessar a pandemia da melhor forma (Duarte, Silva \& Bagatini, 2021) e preservar a saúde mental dos enfermeiros durante a pandemia de COVID-19 é um desafio global muito importante (Galletta et al., 2021). Pois os mesmos não serão úteis para ninguém se eles próprios não forem saudáveis e é por isso que é de primordial importância fornecer-lhes recursos de saúde mental, treinamento em resiliência e aconselhamento em abundância (Sharma et al., 2021).

A enfermagem que já trabalha em um cenário de cargas horárias exaustivas, más condições de trabalho, deficiência no dimensionamento de pessoal, poucos recursos materiais, desvalorização e baixa remuneração (Luz et al., 2021). E em meio à pandemia o que era ruim ficou pior para esses trabalhadores que ficaram na linha de frente no combate a um inimigo invisível, ocasionando o aumento da carga de trabalho, o receio de contaminação pelo vírus, a utilização dos EPIs, a falta de estrutura e as condições insalubres dos serviços de saúde (Luz et al., 2020). Por se tratar de trabalhadores que estão em contato direto com pacientes positivos ou com suspeita de Covid-19, os profissionais de enfermagem representam o grupo que mais sofreram repercussões na saúde mental com implicações psíquicas, transtornos psicológicos e psiquiátricos (Santana et al., 2020).Sem 
falar que estão a mercê do processo de precarização, instabilidade trabalhista e financeira, flexibilização do trabalho com extensa carga horária e baixos salários, obrigando-os a duplas jornadas para complementação salarial (Luz et al., 2020).

Esses funcionários estão acostumados a fornecer cuidados centrados no paciente e na família e no cenário pandêmico atual não podiam permitir visitas, apesar da terrível acuidade dos pacientes (Crowe et al., 2021).Fatores que contribuíram bastante para o impacto psicológico e social negativo e perturbador na vida desses colaboradores foram a resposta dos governos e das políticas de saúde e a capacidade de aquisição de recursos humanos e materiais e o aumento de informações falsas a respeito da pandemia da Covid-19 (Sánches-sánches et al., 2021). Já que a existência das mídias sociais e seu grande alcance é uma novidade da COVID-19 em relação aos surtos anteriores, esta epidemia de desinformação se espalha mais rápido que o vírus, gerando insegurança e angústia (Nabuco, Oliveira \& Afonso, 2020).

Pesquisa recente defende que deve haver sensibilização quanto ao manejo cuidadoso das notícias, tendo em vista os perigos que a disseminação desenfreada de informações pode trazer para o sistema de saúde e em como isso pode afetar, de forma negativa, o crescente número de indivíduos com a COVID-19 que precisam de cuidados emergenciais e de terapia intensiva (Alencastro \& Melo, 2021).Além de fornecer as informações corretas, de como o vírus é transmitido, das medidas protetivas, da importância do isolamento social e da higienização das mãos, é necessário obter informações sobre a realidade do impacto psicológico causado por esta pandemia, e relacionar esse novo conhecimento com o gerado em outras pandemias anteriores (Pozo-herce et al., 2021). Esses fatores podem contribuir para a melhoria da saúde mental do enfermeiro (Ohue et al., 2021).

A carga de trabalho mental pode impactar negativamente na qualidade de vida e no trabalho do enfermeiro (Nikeghbal et al., 2021). Diante desse contexto, todas essas repercussões na saúde mental dos profissionais de enfermagem que estão no enfrentamento da pandemia da Covid-19 conduziram ao adoecimento psíquico desses trabalhadores, identificando-se altos níveis de depressão e ansiedade, principalmente no grupo do sexo feminino de cor ou raça parda (Santos et al., 2021).Como a enfermagem é composta, majoritariamente, por mulheres, estudo retrata um desequilíbrio na carga entre o trabalho e a vida doméstica, desencadeando exaustão e podendo levar à depressão grave e síndrome de Burnout. (Dal'bosco et al., 2020).

Entre os trabalhadores da saúde, são os profissionais da Enfermagem que representam na sua maioria um destaque exemplar na hora de combater e de prestar assistência especializada nos serviços públicos e privada, sendo essenciais e considerados a peça-chave na estrutura das profissões em saúde (Pereira et al., 2021).Por isso, foram reconhecidos pela população como protagonistas e considerados como "super-heróis" pelo seu desempenho no combate a um inimigo invisível que é a Covid-19. A experiência de trabalhar durante a pandemia da COVID-19 representou um evento traumático para os enfermeiros, mas ofereceu-lhes oportunidades de crescimento pessoal e profissional (Fontanini et al., 2021) e ficará na história da vida de cada um que sobreviveu a esse momento histórico.

\section{Categoria 3:Recursos de apoio dos profissionais de enfermagem no enfrentamento ao COVID-19}

Estudos recentes destacam que o bem-estar dos profissionais de saúde é uma preocupação adicional, porque seu trabalho é fundamental para a prevenção e o cuidado de pacientes infectados (Linares et al., 2021). E em meio à crise devastadora e caótica provocada pela COVID-19, é preciso cuidar da saúde de quem cuida (Souza et al., 2021). Em virtude ao enfrentamento dessa doença, intervenções psicológicas voltadas para os profissionais de enfermagem vêm desempenhando um papel extremamente importante para configuração do atual cenário. Schmidt et al., (2020) afirmam que intervenções psicológicas voltadas tanto à população geral quanto aos profissionais da saúde desempenham um papel central para lidar com as implicações na saúde mental em decorrência da pandemia do novo coronavírus. Cuidar de pacientes com a COVID-19 teve e tem um impacto negativo desenvolvendo o medo, a ansiedade e os sintomas depressivos, principalmente nos profissionais que estão lidando diretamente com pacientes contaminados e em situações de risco iminente de morte. No entanto, quanto 
maior foi o clima de segurança hospitalar percebido, menores foram os sintomas psicológicos dos enfermeiros (Cho et al., 2021).

Segundo Ramos-Toescher et al., (2020), para um melhor entendimento das repercussões psicológicas e psiquiátricas de uma pandemia, é preciso levar em consideração as principais implicações e emoções envolvidas antes, durante e após o evento. O bem-estar psicossocial dos profissionais de enfermagem é fundamental no contexto de uma pandemia. Por isso, é preciso orientar esses trabalhadores, apresentar-lhes informações que promovam o autocuidado, inclusive quanto à própria saúde mental, mesmo no contexto de tão grave estresse (Brasil, 2020).

Cuidar das necessidades básicas e usar estratégias úteis de enfrentamento - garantir descanso e descansar durante o trabalho ou entre os turnos, comer alimentos suficientes e saudáveis, praticar atividade física, manter contato com familiares e amigos; evitar usar estratégias inúteis de enfrentamento, como tabaco, álcool ou outras drogas, são alguns cuidados e recomendações para os profissionais (Iasc, 2020).

Prado et al., (2020) afirmam que todas as intervenções são baseadas para o acolhimento e emoções desses trabalhadores, sempre agir com empatia e sensibilidade de acordo com a base da comunicação terapêutica que é realizada através do meio da escuta ativa e qualificada, mantendo o foco no enfrentamento eficaz, na resolução dos problemas, na esperança e pensamentos positivos, com o intuito de provocar respostas psicoemocionais adaptativas e saudáveis. Todos os trabalhadores que respondem ao surto de COVID-19 devem ter acesso a fontes de apoio psicossocial, por outro lado esses profissionais apresentam pouca adesão ao tratamento psicológico, alegando falta de tempo e cansaço pela sobrecarga de trabalho (Schmidt, 2020).

\section{Conclusão}

Na presente pesquisa foi possível enfatizar a importância dos profissionais de enfermagem no enfretamento do novo coronavírus, se tornando essencial em uma situação de emergência, mais ao mesmo tempo desgastante por diversos fatores como a desvalorização desses colaboradores, a sobrecarga de trabalho, a baixa remuneração, as condições precárias no ambiente de trabalho, a escassez ou ausência dos Equipamentos de Proteção Individual (EPIs). Essa situação acarretou vários impactos no adoecimento psíquico desses trabalhadores, dentre eles os de maiores repercussões foram: a depressão, a ansiedade, o desenvolvimento da Síndrome de Burnout, causando o medo, a angústia, o estresse pós-traumático e a insônia. Diante disso, intervenções psicológicas seriam de suma importância, já que essas implicações afetam diretamente na qualidade de vida desses autores e na assistência prestada ao paciente.

Portanto, o estudo estimula pesquisas adicionais sobre a temática, bem como realizar levantamentos sobre esses impactos na saúde mental dos profissionais de enfermagem que estão na linha de frente ao combate da Covid-19, traz consigo um importante peso nas intervenções psicológicas. São necessárias ações estratégicas individuais para melhor atender as necessidades desses profissionais que necessitam de ajuda psicossocial, minimizando os efeitos emocionais e agravos psicológicos.

Por fim sugere-se que haja o desenvolvimento de estudos sobre o conteúdo em questão para que a discussão a respeito destes desafios tenham fundamentos para o desenvolvimento de estratégias que possam melhorar a qualidade da saúde física e emocional dos profissionais de enfermagem diante deste cenário. 


\section{Referências}

Alencastro, A. D. S. A., \& Melo, E. S. J. (2021). Reflexões acerca da "infodemia" relacionada à COVID-19. Revista Mineira de Enfermagem, 25, 1-5.

Alves, J. C. R., \& Ferreira, M. B. (2020). Covid-19: reflexão da atuação do enfermeiro no combate ao desconhecido. Enfermagem em Foco, 11 (1. ESP).

Barbosa, D. J., et al. (2020). Fatores de estresse nos profissionais de enfermagem no combate à pandemia da COVID-19: síntese de evidências. Comunicação em Ciências da Saúde, 31, 31-47.

Brasil, M. S. (2020b). Secretaria de Atenção Primária à Saúde. Nota Técnica - Atenção a pessoas com doenças crônicas na APS diante da situação de pandemia de Covid-19 (Coronavírus). https://atencaobasica.saude.rs.gov.br/upload/arquivos/202005/04091032-nt-atencao-as-pessoas-com-doencas-cronicasna-aps.pdf

Brasil, M. S. (2020c). Saúde mental e atenção psicossocial na pandemia Covid. Recomendações para gestores. Fiocruz. http://www.fiocruzbrasilia.fiocruz.br/wp-content/uploads/2020/04/Sa\%C3\%BAde-Mental

Brasil. (2020a). Coronavírus e saúde mental. Tire suas dúvidas aqui! 2020a. Fio Cruz-Brasília. https://www.fiocruzbrasilia.fiocruz.br/coronavirus-e-saudemental-tire-suas-duvidas-aqui

Cho, M. et al. (2021). Fatores que afetam a saúde mental das enfermeiras coreanas de primeira linha durante a pandemia de COVID-19. Inter Nursin Rev, $68(2), 256-265$.

Clementino, F. S. et al. (2020). Enfermagem na Atenção às pessoas com Covid-19: Desafios na atuação do Sistema COFEN/CORENs. Texto contexto enferm., 29.

Coren - BA, (2020). Equipamentos de Proteção Individual (EPI), conforme Protocolo de Manejo Clínico para o Novo Coronavírus (ANVISA). Conselho Regional de Enfermagem da Bahia. http://ba.corens.portalcofen.gov.br/equipamentos-de-protecao-individual-epi-conforme-protocolo-de-manejo-clinico-parao-novo-coronavirus-anvisa_55197.html

Coren-ES, Responsabilidade: Enfermagem tem importante atuação contra a covid-19. http://www.coren-es.org.br/responsabilidade-enfermagem-temimportante-atuacao-na-luta-contra-a-covid-19_24549.Html

Crowe, S., et al. (2021). The effect of COVID-19 pandemic on the mental health of Canadian critical care nurses providing patient care during the early phase pandemic: A mixed method study. Intensive and Critical Care Nursing, 63, 102999.

Dal'bosco, E. B. et al. (2020). A saúde mental da enfermagem no enfrentamento da COVID-19 em um hospital universitário regional. Rev. Bras. Enferm., 73 (2), e20200434.

David, H. M. S. L. et al. (2021). Pandemia, conjunturas de crise e prática profissional: qual o papel da enfermagem diante da Covid-19? Rev. Gaúcha Enferm., 42 .

Duarte, M. D. L. C., Silva, D. G. D., \& Bagatini, M. M. C. (2020). Enfermagem e saúde mental: uma reflexão em meio à pandemia de coronavírus. Revista Gaúcha de Enfermagem, 42.

Fontanini, R. et al.(2021). Experiências de enfermeiras italianas durante a pandemia COVID - 19: uma análise qualitativa de postagens na Internet.Internacional Nursing Review, 68(2), 238-247.

Galanis, Petros et al. (2021). Nurses' burnout and associated risk factors during the COVID-19 pandemic: A systematic review and meta-analysis.Jornal de enfermagem avançada.

Galletta, M., et al. (2021). Preocupações, preparação e impacto percebido da pandemia de Covid-19 na saúde mental das enfermeiras. Fronteiras em Saúde Pública, 9 .

Gomes, R. (2014). Pesquisa qualitativa em saúde. São Paulo: Instituto Sírio-Libanês de Ensino e Pesquisa.

Greenberg, N. et al. (2021). Mental health of staff working in intensive care during Covid-19. Occupational Medicine. 71 (2), $62-67$.

Humerez, D. C., Ohl, R. I. B., \& da Silva, M. C. N. (2020). Saúde mental dos profissionais de enfermagem do Brasil no contexto da pandemia Covid-19: ação do Conselho Federal de Enfermagem. Cogitare Enfermagem, 25.

Iasc, I. A. S. C. (2020). Como lidar com os aspectos psicossociais e de saúde mental referentes ao surto de COVID-19. Guia preliminar. Versão 1.5. https://opascovid.campusvirtualsp.org/sites/opascovid.campusvirtualsp.org/files/como_lidar_com_os_aspectos_psicossociais_e_de_saude_mental_referentes_ ao_surto_de_covid-19_.pdf

Linares, L. et al.The repercussions of perceived threat from COVID-19 on the mental health of actively employed nurses. International Journal of Mental Health Nursing., 30 (3), 724-732.

Luz, D. C. R. P. et al. (2021). Burnout e saúde mental em tempos de pandemia de COVID -19: revisão sistemática com metanálise. Nursing (São Paulo). 24(276), 5714-5725.

Luz, E. M. F. et al. (2020). Repercussões da Covid-19 na saúde mental dos trabalhadores de enfermagem. Revista de Enfermagem do Centro Oeste Mineiro, 10 .

Miranda, F. B. G. et al. (2021). Sofrimento psíquico entre os profissionais de enfermagem durante a pandemia da COVID-19: Scoping Review. Escola Anna Nery, 25. 
Moreira, A. S. \& Lucca, S. R. (2021). Apoio psicossocial e saúde mental dos profissionais de enfermagem no combate ao covid-19. Enfermagem em Foco, 11 (1).

Nabuco, G., Oliveira, M. H. P. P. \& Afonso, M. P. D. (2020). O impacto da pandemia pela COVID-19 na saúde mental: qual é o papel da Atenção Primária à Saúde? Revista Brasileira de Medicina de Família e Comunidade, 15 (42), 2532.

Nikeghbal, K. et al. (2021). Covid-19 effects on the mental workload and quality of work life in Iranian nurses. Annals of Global Health, 87 (1).

Ohue, T. et al. (2021). Mental health of nurses involved with COVID-19 patients in Japan, intention to resign, and influencing factors. Medicine, 100 (31).

Oliveira, G. S. et al. (2020). Saúde Mental em tempos da Pandemia da COVID-19: Concepções dos trabalhadores da Atenção Primaria a Saúde. Research, Society and Development, 9 (100), e9449109339-e9449109339.

Opas. (2020). Folha Informativa: Conselhos sobre doença coronavírus (COVID-19) para o público. https://www.who.int/pt/emergencies/diseases/novelcoronavirus-2019/advice-for-public?gclid=CjwKCAjwm7mEBhBsEiwA_of-

Page, M. J. et al. (2021). The PRISMA 2020 statement: an updated guideline for reporting systematic reviews. Bmj, 372.

Pereira, J. et al. (2021). Os desafios da enfermagem no enfrentamento ao Covid-19. Brazilian Journal of Development, 7 (2), $14839-14855$.

Pozo-herce, D. et al. (2021). Psychological impact on nursing professionals at the Rioja Health Service (Spain) due to the SARS-CoV-2 virus. Jornal Internacional de Pesquisa Ambiental e Saúde Pública ,18 (2), 580.

Pozo-Herce, D. et al. (2021). Psychological impact on the nursing professionals of the rioja health service (Spain) due to the SARS-CoV-2 virus. International Journal of Environmental Research and Public Health, 18 (2), 580.

Prado, A. D. et al. (2020). A saúde mental dos profissionais de saúde frente à pandemia do Covid-19: uma revisão integrativa. Revista Eletrônica Acervo Saúde.46, 1-9.

Queiroz, A. M. et al. (2021). O 'NOVO’da COVID-19: impactos na saúde mental de profissionais de enfermagem? Acta Paulista de Enfermagem, 34.

Ramos-toescher, A. M. et al. (2020). Saúde mental de profissionais de enfermagem durante a pandemia de COVID-19: recursos de apoio. Esc. Anna Nery, 24 .

Sánchez-Sánchez, E. et al. (2021). Impacto da pandemia do COVID-19 na saúde mental de enfermeiras e técnicos auxiliares de enfermagem - uma pesquisa online voluntária. Jornal Internacional de Pesquisa Ambiental e Saúde Pública, 18 (16), 8310.

Technicians-A Voluntary Online Survey. Int. J. Environ. Res. Public Health. Espanha, 18 (16), 8310.

Santana, N. et al. (2020). Segurança dos profissionais de saúde no enfrentamento do novo coronavírus no Brasil. Esc. Anna Nery. 24.

Santos, K. M. R. et al. (2021). Depressão e ansiedade em profissionais de enfermagem durante a pandemia da covid-19. Escola Anna Nery, 25.

Santos, W.A. etal. (2020). O impacto da pandemia da COVID-19 na saúde mental dos profissionais de saúde: revisão integrativa. Research, Society and Development, [S. l.], 9(8), e190985470.

Schmidt, B. et al. (2020). Saúde mental e intervenções psicológicas diante da pandemia do novo coronavírus (COVID-19). Estudos de psicologia, 37.

Sharma, S. K. et al. (2021). Anxiety, depression and quality of life (QOL) related to COVID-19 among frontline health care professionals: A multicentric cross-sectional survey. J Family Med Prim Care., 10 (3), 1383-1389.

Souza, N. V. O. et al. (2021). Trabalho de enfermagem na pandemia da covid-19 e repercussões para a saúde mental dos trabalhadores. Revista Gaúcha de Enfermagem, 42.

Varghese, A. et al. (2021). Declínio na saúde mental de enfermeiras em todo o mundo durante COVID-19: Uma revisão sistemática e meta-análise. Journal of global health, 11 .

Who. World Health Organization. (2019). Coronavirus disease (COVID-19) pandemic. Geneva.who.int/emergencies/diseases/novel-coronavirus-2019. 